\title{
Epidermal and follicular calciphylaxis
}

Solomon AR, Comite SL, Headington JT. Epidermal and follicular calciphylaxis. J Cutan Pathol 1988: 15: 282-285.

A patient with secondary hyperparathyroidism due to chronic renal failure developed epidermal and follicular calcification without concomitant dermal calcification in the lesions of toxic epidermal necrolysis. We propose that the combination of keratinocyte necrosis and an elevated serum calcium-phosphorus product resulted in epidermal calciphylaxis.

\section{A. R. Solomon, ${ }^{1}$ S. L. Comite, ${ }^{2}$ J. T. Headington ${ }^{3}$}

Departments of ${ }^{1}$ Dermatology and Pathology University of Texas Medical Branch, Galveston, 2Dermatology New York University School of Medicine, ${ }^{3}$ Pathology and Dermatology, The University of Michigan Medical Center, Ann Arbor, U.S.A.

Alvin R. Solomon, M.D., Department of Dermatology, University of Texas Medical Branch, Galveston, TX 77550, U.S.A.

Accepted April 4, 1988.
Although calcification of the dermis and subcutis takes several different histological forms, calcification of the epidermis and follicular infundibula alone has not, to our knowledge, been previously reported in other than an experimental setting $(1,2)$. We herein report a patient with secondary hyperparathyroidism due to chronic renal failure who developed epidermal and follicular calcification without concomitant dermal calcification in the lesions of toxic epidermal necrolysis.

\section{Case report}

A 40-year-old white male with a long history of systemic lupus erythematosus and chronic renal failure was admitted for evaluation of fever and oral mucosal ulcers.

The patient initially developed proteinuria 15 years prior to admission and he had required dialysis 2 years prior to admission. For 2 years prior to admission he was noted to have secondary hyperparathyroidism and numerous determinations of serum levels of calcium and phosphorus exceeded a

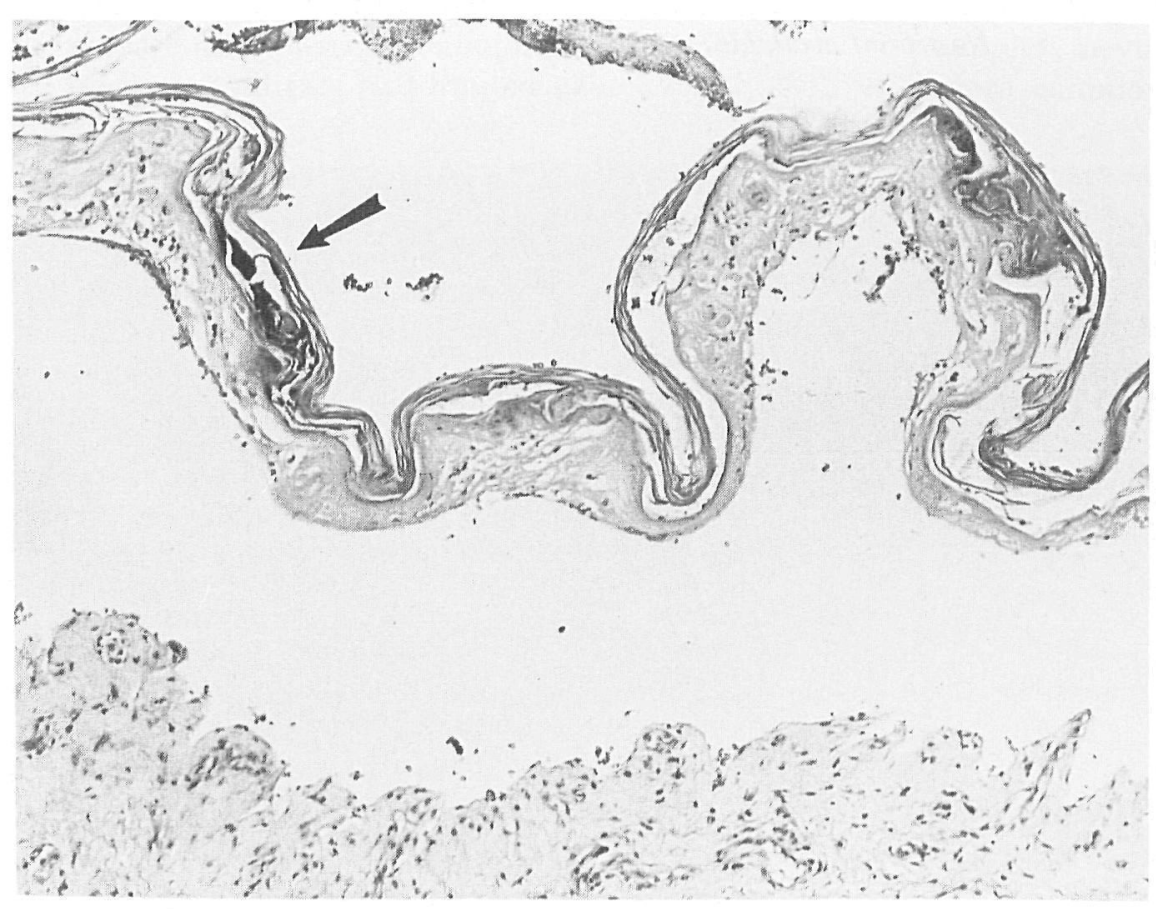

Fig. 1. The epidermis is completely necrotic and separated from the dermis at the level of the epidermal-dermal junction. The arrow points to basophilic granular material beneath the stratum corneum and in the stratum granulosum $(\mathrm{H} \& \mathrm{E}, \times 63)$. 
Fig. 2. Linear granular calcium deposits within the stratum granulosum (von Kossa, × 200).

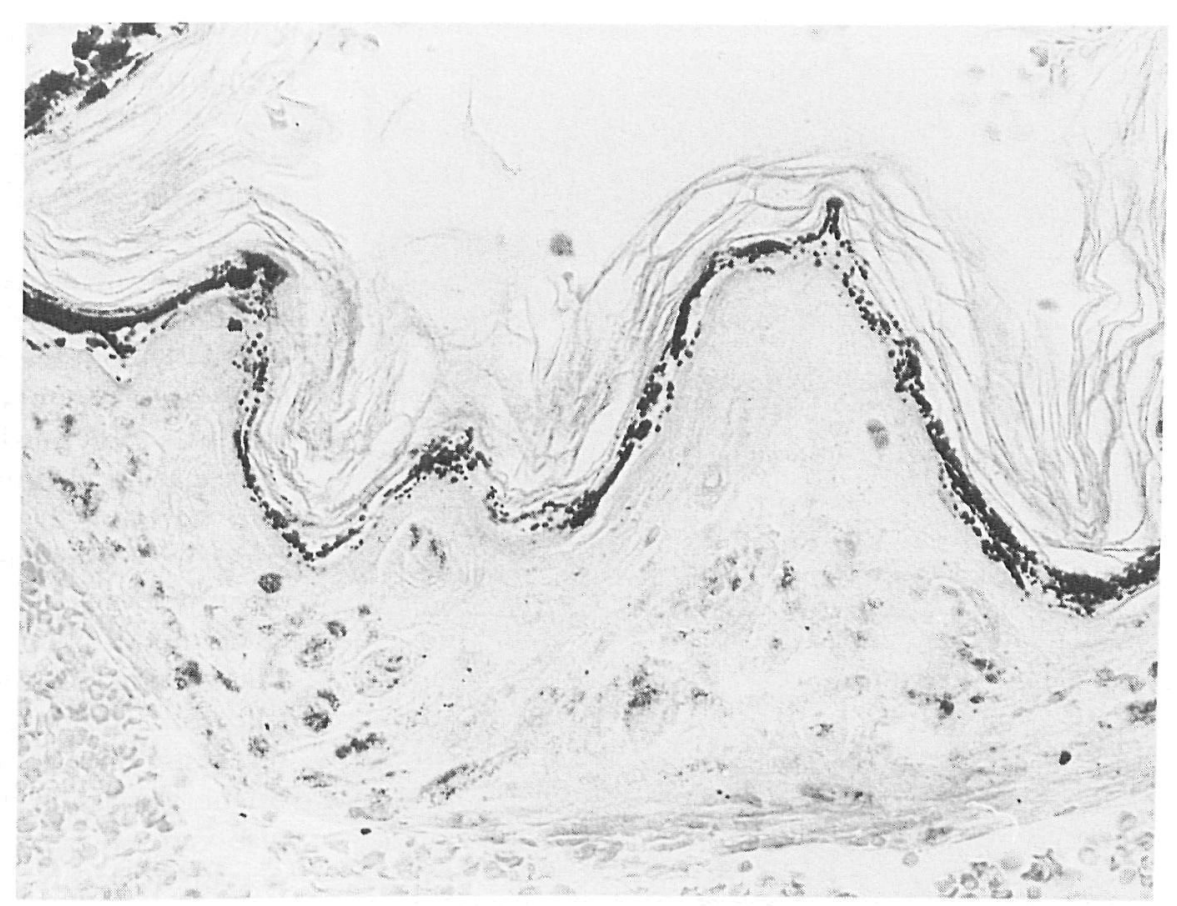

calcium-phosphorus product of 70. Four months before admission erythema multiforme was diagnosed and thought to be secondary to one of his medications which included minoxidil, propranolol, aluminum hydroxide gel, and cephalexin.

On physical examination the patient was noted to be cachectic and febrile. Numerous $5-10 \mathrm{~mm}$ in diameter ulcers were present on the lips and buccal mucosa bilaterally. The serum urea nitrogen (BUN) was $104 \mathrm{mg} / 100 \mathrm{ml}$ (normal $=8-20)$, serum creatinine $17.9 \mathrm{mg} / 100 \mathrm{ml}$ (normal $=0.6-1.3$ ), serum calcium $7.4 \mathrm{mg} / 100 \mathrm{ml}$ (normal $=8.5-10.5)$, serum phosphorus $11.5 \mathrm{mg} / 100 \mathrm{ml}$ (normal $=2.5-4.5)$ and the serum albumin was $2.7 \mathrm{mg} / 100 \mathrm{ml}$ (normal = $3.5-5.5)$.

The patient was treated with $60 \mathrm{mg}$ of prednisone per day for a presumed flare of his lupus erythematosus. Phenytoin sodium was added because of an observed seizure. Four days after starting this latter medication, the skin was noted to be sloughing in large sheets from his back. Nikolsky's sign was positive. A clinical diagnosis of toxic epidermal necrolysis presumably secondary to phenytoin sodium was made and a biopsy was taken from the back. The phenytoin sodium was discontinued and replaced by carbamazepine. Prednisone was continued at the same dose since the clinical diagnosis was lupus cerebritis. Complete exfoliation of the skin on the patient's back, as well as smaller isolated areas of exfoliation on the chest and arms, were present. Topical treatment consisted of only saline soaks. Within several days, the denuded areas began to heal. The patient then refused further treatment and left the hospital.

At the time of biopsy, clinical examination of the areas of skin exfoliation did not reveal any evidence of gross calcification. The skin was soft and pliable. Histologically the epidermis was separated from the underlying dermis. Full-thickness necrosis of the epidermis and follicular infundibula was present along with scant lymphocytic infiltrates in the underlying dermis (Fig. 1). The histologic diagnosis was toxic epidermal necrolysis. Aggregates of dark blue granules were present beneath the stratum corneum and within the stratum granulosum with routine hematoxylin and eosin staining (Fig. 1, arrow). These aggregates stained black with the von Kossa stain. In addition, linear finely granular von Kossa positive material was present in the stratum granulosum throughout the specimen (Fig. 2). Basophilic aggregates similar to those in the epidermis were seen in the necrotic follicular infundibula (Fig. 3). No von Kossa positive staining was noted in the dermis.

\section{Discussion}

Calcium deposition in soft tissues is perhaps best divided into four types based on the presence or absence of abnormally elevated serum calcium or phosphorous levels. In dystrophic calcification, calcium salts are deposited in sites of disease or injury within soft tissues but the serum levels of calcium 


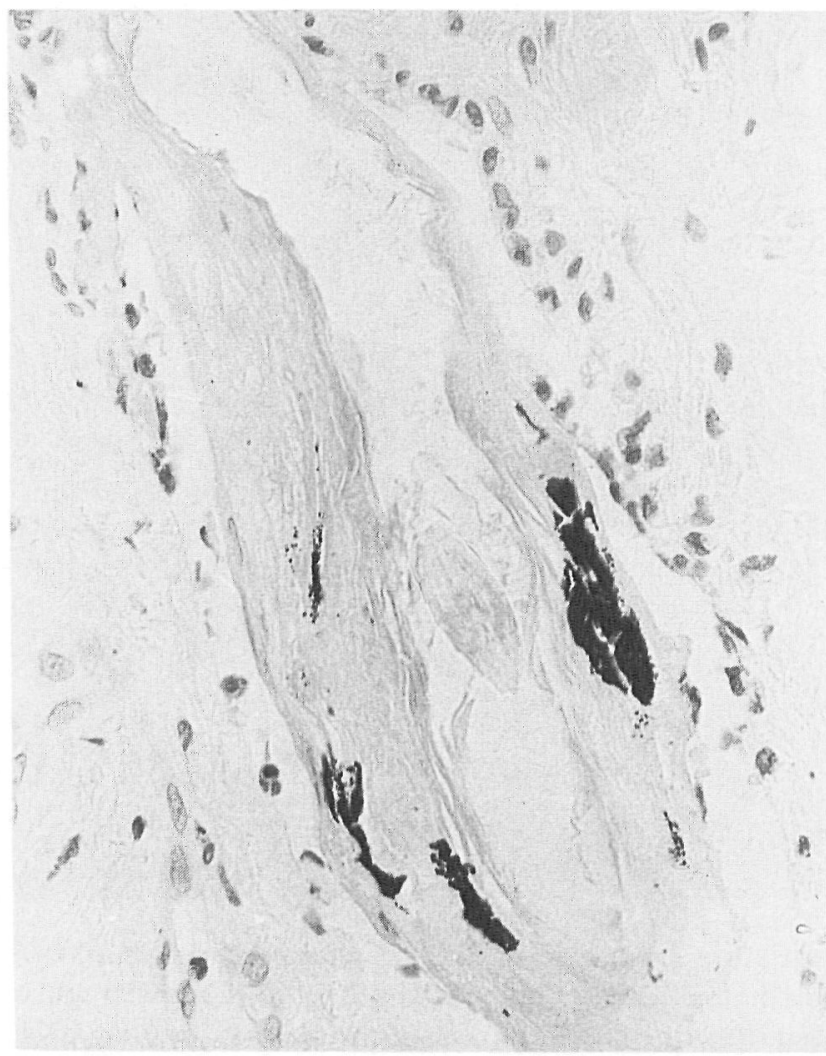

Fig. 3. Aggregates of calcified material present within a necrotic follicular infundibulum (von Kossa, $\times 400$ ).

and phosphorous are normal (1). Calcification in an acne cyst is an example of dystrophic calcification. Metastatic calcification is characterized by the deposition of calcium salts within normal soft tissues (1). In this type of pathologic calcification, the serum levels of either calcium or phosphorous or both are elevated. These elevated levels result in a calcium-phosphorous product (the level of the serum calcium multiplied by the level of the serum phosphorous) greater than 70 (3). It is believed that this abnormally high calcium-phosphorous product, possibly in association with other metabolic abnormalities such as acidosis, is responsible for the deposition of calcium salts within otherwise normal soft tissues. Metastatic calcification has frequently been reported in association with secondary hyperparathyroidism due to chronic renal failure. However, the calcium deposition has been limited to the dermis and subcutis (4-6). A third type of calcium salt deposition is idiopathic calcification. This form of soft tissue calcification is associated with normal serum levels of calcium and phosphorous and is characterized by massive deposition of calcium salts in previously normal soft tissues (1). Tumoral calcinosis and idiopathic scrotal calcinosis are the prototype diseases of this type of calcification. The fourth type of soft tissue calcification has been termed cal- ciphylaxis (2). The concept of calciphylaxis was popularized by Selye in the early 1960's (2). Selye defined calciphylaxis as "a condition of induced systemic hypersensitivity in which tissues respond to appropriate challenging agents with precipitous, though sometimes evanescent local calcification" (2). Two forms of calciphylaxis, topical and systemic, were described. Topical calciphylaxis was induced by contact of a substance called a direct challenger with the target tissue. The experimental animal was previously sensitized systemically with a calcification promoter called the calcifer. Parathyroid hormone is a potent naturally occurring calcifer. Selye experimented primarily with subcutaneous injections of the direct challenger. He primarily used metal salts as a direct challenger but found that certain organic compounds such as egg white or egg yolk could also act in a similar manner. Interestingly, he found that mild mechanical trauma of the skin such as epilation or skin pinching was also very effective in inducing local calcification. In one photograph (Plate I-F) from his 1962 text, Calciphylaxis, he shows calcification in the follicular epithelium after simple epilation in a rat previously sensitized with dihydrotachysterol, a potent calcifer (2). Our patient had secondary hyperparathyroidism due to chronic renal failure. Although the epidermal calcification may have simply been the result of the elevated serum calcium-phosphorous product, many patients in chronic renal failure suffer this pertubation. We propose that the additional stimulus of epidermal necrosis secondary to toxic epidermal necrolysis acted as a direct challenger as conceived and described by Selye with the end result being local epidermal calcification. In essence, epidermal calciphylaxis is possibly a combination of metastatic calcification (hyperparathyroidism with a high calcium-phosphorous product) and dystrophic calcification (local tissue injury).

It is interesting that the calcium deposits were localized to the upper granular layer of the epidermis. Menon et al. have elegantly demonstrated that in mouse epidermis the highest concentration of both intracellular and extracellular calcium ions is found in the upper granular layer (7). With the altered calcium metabolism that occurred in our patient, the zone of the epidermis with the highest concentration of calcium ions would be a likely site for precipitation of calcium salts.

The von Kossa staining reaction is not specific for calcium (8). In this reaction, silver nitrate which is in the von Kossa solution reacts with the calcium anion complex. The anions, usually phosphate or carbonate are then precipitated as an insoluble black silver-anion complex (8). However, in a patient in chronic renal failure with secondary hyperparathyroidism, calcium salts are present in such a 
high concentration that the stain is virtually specific for calcium salt deposits.

In conclusion, we report the striking histologic finding of epidermal calcification following toxic epidermal necrolysis in a man with secondary hyperparathyroidism due to chronic renal failure. We propose that the epidermal calcification was due to epidermal calciphylaxis resulting from the specific injury of toxic epidermal necrolysis in conjunction with a high serum calcium-phosphorous product.

\section{References}

1. Lever WF, Schaumberg-Lever G. Histopathology of the skin. Philadelphia: Lippincott, 1983: 420-421.
2. Selye H. Calciphylaxis. Chicago: University of Chicago Press, 1962: 1.

3. Kerr DNS. Chronic renal failure. In: Beeson PB, McDermott W, eds. Textbook of medicine. Philadelphia: Saunders, 1975: 1100.

4. Parfitt AM. Soft-tissue calcification in uremia. Arch Intern Med 1969: 124: 544.

5. Posey RE, Ritchie EB. Metastatic calcinosis cutis with renal hyperparathyroidism. Arch Dermatol 1967: 95: 505.

6. Katz AI, Hampers CL, Merrill JP. Secondary hyperparathyroidism and renal osteodystrophy in chronic renal failure. Medicine 1969: 48: 333.

7. Menon GK, Grayson S, Elias PM. Ionic calcium reservoirs in mammalian epidermis: Ultrastructural localization by ioncapture cytochemistry. J Invest Dermatol 1985: 84: 508.

8. Shechan DC, Hrapchak BB. Theory and practice of histotechnology. St. Louis: Mosby, 1980: 227. 
This document is a scanned copy of a printed document. No warranty is given about the accuracy of the copy. Users should refer to the original published version of the material. 